\title{
Technologies for Water Resource Management: An Integrated Approach to Manage Global and Regional Water Resources
}

\author{
W. C. Tao \\ M. J. Fluss \\ A. F. B. Tompson \\ D. L. Ermak \\ S. Niemeyer
}

March 23, 1998

This is an informal report intended primarily for internal or limited external distribution. The opinions and conclusions stated are those of the author and may or may not be those of the Laboratory.

Work performed under the auspices of the U.S. Department of Energy by the Lawrence Livermore National Laboratory under Contract W-7405-Eng-48 


\section{DISCLAIMER}

This document was prepared as an account of work sponsored by an agency of the United States Government Neither the United States Government nor the University of California nor any of their employees, makes any warranty, express or implied, or assumes any legal liability or responsibility for the accuracy, completeness, or usefulness of any information, apparatus, product, or process disclosed, or represents that its use would not infringe privately owned rights Reference herein to any specific commercial product, process, or service by trade name, trademark, manufacturer, or otherwise, does not necessarily constitute or imply its endorsement, recommendation, or favoring by the United States Government or the University of California The views and opinions of authors expressed herein do not necessarily state or reflect those of the United States Government or the University of California, and shall not be used for advertising or product endorsement purposes

This report has been reproduced directly from the best available copy

Available to DOE and DOE contractors from the Office of Scientific and Technical Information

PO Box 62, Oak Ridge, TN 37831

Prices available from (423) 576-8401

Available to the public from the National Technical Information Service

US Department of Commerce

5285 Port Royal Rd,

Springfield, VA 22161 


\title{
Technologies for Water Resource Management: An Integrated Approach to Manage Global and Regional Water Resources
}

\author{
March 23, 1998
}

\begin{abstract}
William C. Tao, Chemistry and Material Science Directorate Michael J. Fluss, Chemistry and Materials Science Directorate Andrew F. B. Tompson, Environmental Programs Directorate Donald L. Ermak, Environmental Programs Directorate Sidney Niemeyer, Chemistry and Material Sciences Directorate
\end{abstract}

Lawrence Livermore National Laboratory LDRD Tracking \# 97-FS-005 


\section{Executive Summary}

Recent droughts in California have highlighted and refocused attention on the problem of providing reliable sources of water to sustain the State's future economic development. Specific elements of concern include not only the stability and availability of future water supplies in the State, but also how current surface and groundwater storage and distribution systems may be more effectively managed and upgraded, how treated wastewater may be more widely recycled, and how legislative and regulatory processes may be used or modified to address conflicts between advocates of urban growth, industrial, agricultural, and environmental concerns.

California is not alone with respect to these issues. They are clearly relevant throughout the West, and are becoming more so in other parts of the US. They have become increasingly important in developing and highly populated nations such as China, India, and Mexico. They are critically important in the Middle East and Southeast Asia, especially as they relate to regional stability and security issues. Indeed, in almost all cases, there are underlying themes of "reliability" and "sustainability" that pertain to the assurance of current and future water supplies, as well as a broader set of "stability" and "security" issues that relate to these assurances--or lack thereof--to the political and economic future of various countries and regions. In this latter sense, and with respect to regions such as China, the Middle East, and Southeast Asia, water resource issues may take on a very serious strategic nature, one that is most illustrative and central to the emerging notion of "environmental security."

In this report, we have identified a suite of technical tools that, when developed and integrated together, may prove effective in providing regional governments the ability to manage their water resources. Our goal is to formulate a framework for an Integrated Systems Analysis (ISA):

- As a strategic planning tool for managing regional water resources;

- As an evaluation tool for selecting appropriate remediation technologies for reclaiming water; and

- As an assessment tool for determining the effectiveness of implementing the remediation technologies.

We have included a discussion on the appropriate strategy for LLNL to integrate its technical tools into the global business, geopolitical, and academic communities, whereby LLNL can form partnerships with technology proponents in the commercial, industrial, and public sectors 


\section{Introduction}

\section{The Importance of Water Resource Management}

A recent study by the California Department of Water Resources estimated that "by the year 2020, without additional facilities or improved water management, California could experience annual water shortages of up to 9 million acre feet (twice the storage capacity of Shasta reservoir) during dry years " From the perspective of many suppliers and users, water supplies in the state are becoming increasingly less reliable. Just the economic implications of managing a real or perceived limited supply of water for the state into the next century are very costly. Indeed, increased competition for water resources is making their management a crucial and complicated issue involving many different political, legal, economic, and social factors

California is, in many respects, "ahead of the pack" in dealing with these issues, but suffers from lack of progress in many significant areas. The State has one of the most sophisticated surface water storage and delivery systems in the world (State Water Project; Central Valley Project). The Metropolitan Water District in Southern California, for example, has begun the construction of an expensive $\$ 2$ billion reservoir to reduce their susceptibility to future drought. The Orange County Water district is planning to accelerate their aggressive water reuse and groundwater recharge practices so as to become independent of imported supplies. Nevertheless, uncertainties continue to make planning and management of surface water flows and their storage and distribution systems difficult over both the short and long terms (flooding versus drought); groundwater allocation and use practices are notoriously uncoordinated, unmanaged, and abused; and the economic differences between agricultural and urban water practices are quite wide.

\section{The International Strategic Nature of the Problem}

The People's Republic of China (PRC) is one of the world's fastest developing nations. It faces a major crisis in the management, allocation, and quality of its water resources and lacks any systematic or integrated approach to assess the seriousness of the water crisis or to plan an overall improvement of its water resource systems. The crisis is exemplified by the competition for water among the agricultural and industrial interests in the "bread basket" provinces of Sichuan, and the traditional abuse or ignorance of environmental impacts with respect to fertilizers, industrial contamination, and release of poorly treated or untreated domestic wastewaters. Moreover, the crisis is exacerbated further by population growth and the tremendous desire for economic stability and rapid modernization in both the agricultural and industrial sectors.

The Middle East is characterized by an arid climate, growing settlements and populations, and a sparse distribution of water resources that knows no political boundary. Even in the absence of political stress, contention for water resources is a serious issue in the entire region, and is dealt with via a wide spectrum of technical capabilities-ranging from the more modern and sophisticated perspectives in the case of Israel, to the basic and largely uncoordinated approaches in the case of Syria. Given the added tenuous and possibly unstable political relationships existing within Israel and the new Palestinian States, or between Israel and other neighboring countries, water is becoming the strategic resource in the region, and a critical factor in the overall regional security. In the case of the Peace Initiative between Israel and Jordan, the sharing of water resources has become the cornerstone for confidence building and joint regional planning.

Southeast Asia is comprised of the collection of archipelago-like countries called Philippines, Indonesia, Malaysia, and Brunei, and peninsulas such as Thailand, and Singapore. The subterranean hydrologic character of these countries are primarily porous limestone, with both interconnected and isolated pockets 
of freshwater. Over the last two decades, industrialization within these respective countries has resulted in accelerated pumping and extraction of freshwater from the underground acquifers, and in so doing, increased the rate of salt intrusion from the surrounding ocean. Without a planned active recharge program to preserve and rejuvenate the underground acquifers, it is only a matter of time before underground freshwater sources are eliminated. The surface terrain of these countries are primarily mountainous due to the continuous redefinition of the topography by volcanic activity and tectonic movement. Without a strategy for long range planning of catchment facilities, the majority of the precipitation from annual torrential rainfalls leads to immediate runoffs, which contributes to surface and soil erosion and contamination of surface freshwater sources. The governments in these countries, faced with continued population growth and the country's demand to industrialize, are confronted with a monumental task to preserve, regenerate, and plan the long-term use of their available freshwater supply.

\section{Technological Advancements for Managing Water Resources}

Progressive management strategies will be required to find balances among growing urban demands, finite and frequently uncertain supplies, water quality and reuse issues, and other environmental and legal constraints. These, in turn, will require new and more advanced methods for analysis, forecasting, treatment, and abatement to support reliable and responsible policies for addressing these problems in the future.

Over the last decade, LLNL has developed a suite of novel, cutting-edge technical tools for the integrated analysis of surface and subsurface water resources problems. These tools include.

Regional precipitation and riverflow forecasting - a unique coupled approach (CARS) for directly linking short term $(48 \mathrm{hr})$ precipitation forecasts to river flow and river stage predictions to provide a more reliable, real-time basis for making decisions with respect to flood and reservoir management issues

Detail regional 3D groundwater basin modeling studies - a unique large-scale groundwater flow and transport model (PARFLOW) for simulating groundwater flow and chemical migration processes in large, three-dimensional systems

Advanced isotopic measurements for water management applications - a suite of novel and robust isotope techniques used as a powerful diagnostic tool to fingerprint sources of surface and groundwater, track their travel pathways and flow rates, and assess origins of the water's chemical constituents.

In order for these tools to be integrated cohesively, we have delineated, within each technology area, the primary focus of the scientific research in order to enable the integration of these capabilities and to enhance our ability to address problems of interest to potential national and international sponsors. Our efforts should focus on:

1. Achieve more accurate simulations in precipitation and surface hydrology by addressing major issues of uncertainty in our coupled precipitation and surface flow modeling capability, including the ability to treat grid- and subgrid-scale precipitation processes, optimize terrain representations, and improve our surface hydrology models.

2. Enhance the PARFLOW groundwater flow and transport model so that it can address critical groundwater issues for water resource managers and demonstrate its advantages over the widely used MODFLOW model.

3. Develop advanced isotopic tracer technologies for both surface and groundwater applications, with emphasis on the challenging issue of linking water quality, e.g. assessing the origins of the water's chemical constituents and their degradation pathways, with management of water resources. 


\section{LLNL Water Resource Management Technologies}

\section{Reqional precipitation and riverflow forecasting}

LLNL has developed a unique coupled approach for directly linking short term (48 hr) precipitation forecasts to river flow and river stage predictions to provide a more reliable, real-time basis for making decisions with respect to flood and reservoir management issues.

The Coupled Atmosphere-Riverflow Simulation (CARS) system has been assembled at LLNL as a platform to link the Mesoscale Atmospheric Simulation (MAS) model, the Soil-Plant-Snow (SPS) model, and a surface runoff and riverflow model (TOPMODEL). The MAS model predicts regional scale atmospheric dynamics and subsequent rainfall and snowfall within the model domain, while the SPS model is interactively coupled with the MAS model to redistribute snow and rainfall within the upper soil layers, plant canopy, and existing snowpack by various physical processes such as evapotranspiration, infiltration, runoff, and increase/decrease of surface snowpack. The SPS model redistributes water at land surfaces by solving the surface energy and water balance equation with parameterized plant physiology as a function of the season, species, and atmosphere-soil environment. The TOPMODEL is used to "route" rainfall over variably-vegetated topographic surfaces into streams, rivers, and lakes, and also as infiltration into near-surface soils and root zones over times scales consistent with the overall storm events. Infiltration is either redistributed to the atmosphere through plant evapotranspiration processes, accumulated as additional storage in the unsaturated soil zone, or discharged to deeper groundwaters or back to the surface.

In addition, an Automated Land Analysis System (ALAS) has been developed to facilitate direct application of CARS to arbitrary watersheds. ALAS uses digital elevation data to identify the location, boundary, area, and hydrologic characteristics of watersheds and can produce topographic information for a watershed at any desired spatial resolution. To date, LLNL researchers have completed the topographic data sets for the Russian River and the American River basins and are currently working on the Feather River and Lake Shasta Inflow basins.

The CARS system can be nested within large-scale atmospheric data to produce weather predictions and climate research over limited-area domains. At present, the MAS model is used to produce daily numerical weather predictions (NWP) and quantitative precipitation forecasts (QPF) for 48-hr periods, and the water resources and hydroclimate simulations over the entire winter season for California and southwestern United States using the data from the National Meteorological Center. During the January 1995 floods, TOPMODEL closely simulated the river flow at the Hopland gauge station within the Russian River basin The MAS simulated QPF during the January 1995 flood also showed very good accuracy compared to observations.

These activities have received great interest within the state and national arena. As a result of this work, specific interactions and new collaborative activities have been developed with the California Division of Water Resources, National Weather Service, National Center for Atmospheric Research, and locally through a Campus-Laboratory-Collaboration (CLC) project between LLNL, Scripps Institute of Oceanography, UC Davis, and UC Irvine.

\section{Detail regional 3D groundwater basin modeling studies}

LLNL has developed a unique large-scale groundwater flow and transport model (PARFLOW) for simulating groundwater flow and chemical migration processes in large, three-dimensional systems. The original focus of PARFLOW was to enable detailed simulations of contaminant migration and remediation processes in naturally complex (heterogeneous) subsurface formations and to use the power of high performance (parallel) computing to support Monte Carlo uncertainty and risk analysis studies from a probabilistic perspective. 
In a collaboration with the Orange County Water District (OWCD), LLNL researchers applied PARFLOW to the large coastal groundwater basin managed by the District. The novel capabilities of this model (unavailable in most groundwater resource simulation packages) was exploited to support the analysis and design of current and future water management strategies that are now under consideration. These include for most the ability to treat very large 3D problems using massively parallel computing, and the ability to hierarchically increase spatial resolution to very fine levels during the calibration process as required to resolve transport phenomena. OCWD currently manages basinwide groundwater production that provides over $70 \%$ of the drinking water for 2 million residents. They have been able to achieve this by establishing an active groundwater recharge program in which the base flow of the Santa Ana River is purposely reintroduced into the subsurface via diversions into infiltration basins. Future plans call for accelerating this recharge by pumping additional treated wastewaters into these basins from their sewage treatment plant. This will reduce dependence on imported water supplies, but require a more careful understanding of the recharge processes for management purposes. Ultimately, OCWD, like most metropolitan areas that must balance water usage between industrial and urban sectors, is interested in

1. the impacts of additional aquifer recharge, including estimates of which supply wells may produce the additional water and when,

2. residence times of the newly recharged (waste) waters, with respect to when such waters may be safely pumped for later domestic use (following State Division of Health Services guidelines),

3. build up of dissolved salts and organics in groundwater as a result of long term recycling practices,

4 the long term viability of their salt water barrier near the coast (which inject treated waste waters through barrier wells)

The modeling application will ultimately be driven by the more pressing issues of water quality, in addition to water quantity alone. Because of this, it will require a fine degree of spatial resolution to track the migration and residence times of the recharged and recycled waters; this, in turn, easily plays into PARFLOW'S targeted capabilities and makes application of competitive models in a fully 3D mode much more difficult

The OCWD is widely recognized as one of the nation's premier water districts for pioneering innovative approaches to water resource management. The broad OCWD goal is to provide a high-quality, reliable, and affordable water supply, and they are presently focusing on greatly expanding its use of recycled wastewater for groundwater recharge purposes. These activities have received great interest within Orange County and will actually be linked with several isotopic studies of their water being carried out by the isotope sciences division of LLNL.

\section{Advanced isotopic measurements for water management applications}

LLNL has been developing a number of novel and diverse applications of isotope hydrology for solving a number of water resource problems. The isotopic character of water can be used as powerful, diagnostic tool to fingerprint sources of surface and groundwater, track their travel pathways and flow rates, and assess origins of the water's chemical constituents. These can be used as a complement to numerical models for validation and calibration purposes, or in an independent mode as a quick, cost effective alternative for local water resource decision makers to gain insight into system behavior.

LLNL operates a variety of sophisticated facilities for measuring the most minute isotopic compositions on a regular "production mode" basis. Our capabilities include accelerator mass spectrometry for low-level detection of long-live radionuclides $\left({ }^{14} \mathrm{C},{ }^{36} \mathrm{Cl},{ }^{129} \mathrm{I}\right.$ ), noble-gas mass spectrometry (tritium-helium dating, recharge temperatures, artificial tracers), thermal-ionization mass spectrometry $(\mathrm{Sr}, \mathrm{U}, \mathrm{Pb}, \& \mathrm{Nd}$ isotopes), stable-gas mass spectrometry $(\mathrm{H}, \mathrm{O}, \mathrm{C}, \& \mathrm{~N}$ isotopes), ICP-MS (trace element abundance by isotope dilution), and radiation counting techniques using alpha, beta, and gamma detectors. The breadth 
of these isotopic facilities exceed those available at any other laboratory. An added benefit of our breadth of capabilities is that experts on all the various instruments and from varying scientific background collaborate on the design and interpretation of the experimental studies.

Recent work at LLNL has focused mostly on groundwater studies in several areas in California. The earliest project with the Orange County Water District involved identification of an isotopic fingerprint of historically recycled water such that its travel time (age), migration patterns, and chemical evolution of its constituent organic materials could be discerned. LLNL researchers were able to show, for example, that injected wastewaters at their salt water barrier wells took 2.5 years to reach the nearest production well, satisfying an empirical 1-year residence time requirement. Similarly, isotopic methods were used to assess the fate and distribution of OCWD's historically recharged waters introduced through the infiltration basins. Initial results suggest the groundwater flow system is highly stratified, and this will be an important factor in understanding the overall transport pathways away from these basins.

LLNL researchers have also been engaged in a contractual groundwater isotope study for the City of Brentwood and the East Contra Costa Irrigation District. Here, the laboratory's technology has developed and has been used in lieu of any appreciable hydrogeological modeling The results have provided a quantitative framework in which the long-and short-term sustainability of their groundwater resources under various growth and land use scenarios could be more effectively assessed. Recommendations were provided to help:

1. maximize water quality over the planning scenarios,

2. address the long-term need for alternative water supplies,

3. evaluate future groundwater production from a basin scale point of view, and

4. finding previously untapped groundwater supplies in this area.

Recently LLNL researchers conducted surface water study that sought to delineate the sources of water for the very high flow springs in the southern Cascades. These springs are situated in fractured rock in active volcanic regions, and in some areas these springs are the major direct sources of the regional rivers. In general, the isotope results showed that the primary recharge location was the high elevation, high precipitation areas that are up to $50 \mathrm{~km}$ away from the springs. Carbon isotopes also identified three distinct carbon reservoirs, including dissolved carbon from volcanic gas emissions. Preliminary carbon isotope measurements in the Pit River as a function of flow volume suggests that these data might be used to quantify the contributions of different sources as a function of storm intensity.

These examples illustrate LLNL's isotopic approach to water management issues. The scientific accomplishments to date include:

1. developed unique combined isotope approach to generate definitive results for water management, and then demonstrated the viability of such an approach;

2. first to use noble gas abundances for tracing recharge dynamics in young groundwater systems;

3. first to isotopically characterize reclaimed waste water for subsurface tracing;

4. characterized and quantified agricultural recharge in California's Central Valley and linked water quality to water use; and

5. developed isotope mass balance approach to predicting groundwater resource availability.

These achievements and the development of this capability also includes collaborative and funded projects with the Kansas Geological Survey, Yolo County Public Works Department, U.S. Army, California Department of Water Resources (Northern District), U.S. Park Service, U.S. Geological Survey, San Gorgonio Water Pass Agency, Boyle Engineering, Pacific Gas \& Electric, and DOE Nevada Operations Office. 


\section{Ongoing Cutting-Edge Research and Development}

Ongoing Research and Development are focused on three areas:

1. Development of the atmospheric physics submodel capabilities to provide accurate precipitation simulation in the complex mountainous regions of the western US,

a) Fundamental scientific challenge $\cdot$ develop increase capability to more accurately represent the spatial distribution of rainfall over complex topographic regions through improved cloud microphysics submodels and parameterization of sub-grid scale variation of rainfall-runoff processes

2. Expansion of the hydrologic database to key watersheds in the California region where the improved CARS system can be integrated with the groundwater modeling capability (described in the following sections);

a) Fundamental scientific challenge: develop a more sophisticated treatment of surface water components for the PARFLOW groundwater model and demonstrate the application of this model for regional water resource management at an unprecedented degree of spatial resolution

3. A modeling system evaluation study that utilizes the isotope tracer capabilities (described in the following sections) within the selected watershed region.

a) Fundamental scientific challenge. develop isotopic methods for addressing groundwater quality issues of contaminant transport and chemical degradation, and incorporate isotopic data into the PARFLOW model 


\section{Business Development and Marketing Strategy}

Several important and key elements are associated with successful projects, designed and executed so they produce significant scientific and technological contributions, that help decision makers form policies and set priorities and practices in the environmental arena. These elements have allowed LLNL to uniquely exploit the capabilities in Water Resources Management thus far, and include:

- Partner with collaborators and clients early-on to develop a mutual trust and confidence,

- Build on this trust, identify needs and requirements of the clients, and determine how these needs and requirements fit into their analysis resources, and

- Formulate technical resources through research, development and testing around the needs and requirements of the client, i.e., applications dictate the resource requirements and not the other way around.

A list of our local and national collaborators and sponsors are summarized in Appendix I

\section{Business Development Strategy}

The overall strategy to developing both a domestic and international customer base for the Integrated Systems Approach revolves around 1) partnering with the client from the beginning to identify their requirements, 2) applying the Water Resource Management tools to address their needs while concurrently incorporating their input into LLNL's R\&D guidelines for refining and integrating our suite of technical capabilities, and 3 ) working with the client to develop a broader application of the Integrated Systems Approach to analysis and planning.

LLNL should focus the business development strategy on three groups of customers:

Federal Agencies - LLNL researchers should continue to work closely with domestic federal agencies, especially those in California, who are responsible for managing watershed resources. The relationships already built with these customers will allow LLNL to use their arena as a "test bed", and funding already received from these agencies will be leveraged against other investments.

US Industry - LLNL continues to work with several major US Industries with a track record of winning federal procurements for environmental management, restoration, and remediation contracts. The goal is to establish legal and strategic teaming arrangements so that our Integrated Systems Approach will be used for planning various remediation actions.

International Partner - The laboratory should work with China and Middle East countries to establish a partnership for implementing our Integrated Systems Approach for studying their watershed resource management issues and for recommending restoration and remediation actions. This will couple back into our partnership with US Industries for implementing some of LLNL's technologies for water resources cleanup and remediation

This business strategy depends on the development of a programmatic funding base that must include a baseline funder(s) and an agglomeration of smaller projects that provide a sustainable funding base for the Integrated Systems Approach for Water Resources Management. This funding structure will provide LLNL with a steady resource base to invest simultaneously in developing the next generation of cuttingedge technology and in customizing the Integrated Systems Analysis capability to suit the different needs of various customers.

At the writing of this report, the authors believe that LLNL's baseline funding should be derived from federal agencies such as the Departments of Energy, State, Commerce, and Defense. The Integrated Systems Approach to Water Resource Management provides for these funders the tool to engage on an 
international level with countries such as China and global regions such as the Middle East and Southeast Asia in addressing environmental and security issues. The relationship between these water resource issues and national security objectives makes this an especially appropriate environmental initiative for LLNL. This interagency and intergovernmental approach allows LLNL to make an international impact with its science and technology, gain funding from established baseline funding agencies, and fulfill one of its laboratory missions, while minimizing the exposure to risks associated with the politics of water resource management.

\section{Business Marketing and Exit Strategies}

The laboratory's exit plans should be centered on the development of further collaborative work and sponsors in the local and national arena, as well as the initiation of partnerships and additional collaborations in the international arena, with a specific emphasis on China, the Southeast Asia area, and the Middle East. Future work and collaborations must focus on the development of the most appropriate application of our unique and integrated capabilities.

Inroads to the PRC have already been established via the DOE National Labs technical exchange programs with PRC's China Academy of Engineering Physics (CAEP) and China National Nuclear Corporation (CNNC) Institutes. A series of workshops were conducted at LLNL in June, 1996, (Materials Database, Atmospheric Dispersion Modeling) and in Beijing in August (Industrial Ecology, Nuclear Reactor Safety, and Materials Protection and Control) to further develop our partnership with China. LLNL has received an informal request from Israel to establish a lab-to-lab program to address regional stability and security issues. This will serve as the initial framework for partnering with countries in the Middle East.

The incorporation of an industrial infrastructure into an agricultural base society, its impact and consequences in the environmental arena, and the management of resources are the major focus of PRC's "Agenda 21" program. Towards the development of a long term resource investment strategy, PRC has established various Special Administrative Regions (SARs) to foster the demonstration, implementation, and industrial partnerships of environmental related technologies This framework provides an ideal starting point for partnering with the PRC to demonstrate the usefulness of our Integrated Systems Analysis for managing water resources. Our focus with the PRC and Korea will be along the lines of:

- Modeling large-scale atmosphere-soil-crop response for time scales of 48-hr. to a season;

- Predicting the impact of large-scale variability on regional water resources and agriculture;

- Diagnosis of hydro-climate and the response of crops and forests;

- Characterizing the degree of water quality, locating sources of contamination, and mapping the transport of pollutants in rivers and groundwaters (especially for China);

- Anticipating the impact of land-produced water pollution on coastal ecosystem such as the Yellow Sea.

A second important component of the business development strategy is to establish an equitable teaming arrangement with several US Industries, whose main business lines are federal and private contracts for environmental management, restoration, and remediation. This arrangement allows LLNL to receive funds, in the form of both Federal and Non-Federal WFOs, for implementing the Integrated Systems Approach for Water Resources Management and the various environmental remediation technologies that we have developed for the restoration of our own site. The goal is to apply LLNL's Integrated Systems Analysis as a strategic planning tool for managing regional water resources, an evaluation tool for selecting appropriate remediation technologies for reclaiming water, and an assessment tool for determining the effectiveness of implementing the remediation technologies. 


\section{International Business Development Strategy}

In forming the business plan for the application of LLNL's Water Resource Management expertise in the International arena, the laboratory should first focus on The People's Republic of China, Southern Pacific Rim, Hong Kong, South Korea, Singapore, and the Middle East (specifically, Israel). For each of these potential international customer and business partners, we have identified the following metrics as a mean of evaluating the potential of LLNL in establishing a business partnership with the customer and in getting funding for the work:

- Relevance and importance of Water Resource Management to the customer.

- Current interactions and contact between LLNL and Customer, including development of initial contacts, current collaborations, proposals submitted for funding, and work funded at LLNL

- Major Programs anticipated in the next 3-5 years from the customer.

- Major Efforts anticipated in 3-5 years from the international scene

- Current efforts in marketing and business development, including workshops in promoting our product, site visitation, and other collaborations and discussions

\section{The People's Republic of China}

\section{Relevance and importance of Watershed Resource Management to the PRC}

The People's Republic of China (PRC) is one of the world's fastest developing nations facing a major crisis in water resource management, water pollution, and the lack of an integrated systems approach to assess the seriousness of the water crisis in order to develop a strategy for remediation. Without an overall plan on how to manage its water resources, PRC does not have a framework from which to coordinate with the provincial governments in order to implement the necessary technologies, some of which are well developed, to clean up the polluted potable water supply. More importantly, PRC does not have a resource management tool to guide the distribution of their water resources between the agricultural usage and the industrial development sectors, both of which are necessary to be maintained in order to sustain the population and the plan for modernization.

A vivid example of the competition for water resources is found in the province of Sichuan, one of the largest and most populated region located in the central part of the PRC. Surrounded by mountains, which serves as an ideal moderator for the climate and provides a natural water collection and storage system, the province of Sichuan is the "bread basket" for over half the population of PRC. This province is also an industrial development hub for the PRC because of the heavy industrial infrastructure established since W W II (the mountains provided a natural and impenetrable line of defense against the Japanese forces). The Sichuan provincial government is faced with the primary problem of how to distribute the available water supply to the agricultural community and to the industrial and manufacturing sectors booming all over the province. Without guidance from the central government or an understanding of how to collect for, allocate from, reclaim for, and recharge into the watershed, the provincial government is left with the simple policy of first come - with the most money - first served.

The misuse and misallocation of the available water supply has led to a serious contamination of the underground water system, which has often led to fatal consequences for the local population. These sources of contamination include nitrates from the use of fertilizer throughout the agricultural community, discharge of waste water and industrial solvent both onto land and into the rivers, and the leaching of contaminates from storm water discharge into the rivers. The concentrations of various volatile organic contaminants (VOCs) from the toxic solvents used in the paper pulp manufacturing industry alone are many orders of magnitude above our domestic MCLs for these VOCs. This has led to the sporadic 
shutdown of the paper manufacturing industry all over the country in order to allow for the dilution of the VOCs by natural water recharge systems.

The Integrated Systems Approach to Watershed Resource Management can help the PRC and the Sichuan provincial government to establish a plan for storage, allocation, reclamation, and remediation of their water supply. The following is an example scenario of how the PRC can use LLNL's Integrated Systems Analysis:

- Use the Atmospheric Modeling component to determine the cyclical interaction between rainfall, collection, evaporation, and discharge; this will provide basis to plan for collection and storage facilities.

- Use the Isotope Fingerprinting component to determine the surface flowpaths, drainage, and recharge effects on the subsurface hydrology's ability to filter, absorb, and disseminate contaminants; this will provide an identification of the subsurface connectivity between various aquifers.

- Use the Subsurface 3D Modeling component to understand the rate of dispersion of contaminants and evaluate different scenarios of recharge and remediation; this will provide the basis of how to cycle the watershed via recharge and how to plan for remediation of the polluted water.

- Use the entire Integrated Systems Analysis to design an accelerated cleanup plan for various subregions in the Sichuan province; this plan may employ conventional technologies such as Pump and Treat, to advanced technologies such as Capacitive Deionization filtering of contaminants.

Current interactions and contact between LLNL and the PRC

As of the writing of this report, the Department of Energy through several of its National Laboratories (LLNL, LLNL, and SNL) has established a formal channel for interactions with its counterpart, the China Academy of Engineering Physics (CAEP), in the PRC. The objectives of these interactions are to engage the PRC in discussions, technical exchanges, and eventual collaborations in the areas of Nonproliferation, Arms Control, Technologies for Treaty Verification Environmental Remediation, Industrial Ecology, and Advanced Materials for Green Manufacturing. LLNL is currently designated as the lead-lab in the China Lab-to-Lab program and is in the driver seat to design the framework and funding distribution for interactions with the PRC. A series of exchanges between LLNL, DOE, and the PRC have already occurred:

- Four major workshops, held every quarter and located alternately between US and PRC, focused on Nonproliferation Technologies, Arms Control and Treaty Verification, Atmospheric and Underground Dispersion Modeling, and Materials Protection, Control, and Accounting.

- Two additional workshops focused on Materials Database for Industrial Ecology and Methods to Design for the Future, and on Nuclear Power and Reactor Safety.

- Hosted senior officials from the State Science \& Technology Commission, China State Planning Commission, China National Environmental Protection Agency, China National Nuclear Corporation, and the China Academy of Engineering Physics to discuss priorities and opportunities for applying LLNL's Integrated Systems Analysis for Watershed Management

- Several site visitations to areas within the PRC where the watershed resources are corrupted and contaminated

It should be apparent that LLNL has already laid the groundwork and established a protocol in which the laboratory programs are interacting with the PRC. This framework will allow LLNL researchers to establish the necessary connections and advocacy within the PRC government for LLNL to team with the PRC in applying the Integrated Systems Analysis for Water Resources Management. 
Besides the China Lab-to-Lab program within the DOE, there are various other programs between other parts of the DOE with the PRC. Once such program, which is directly relevant to our desire to apply the Integrated Systems Analysis to Water Resources management, is the In-County Study for Environmental Management Program established by the Presidential Task Force on Global Environmental Management. This program, with involvement and support from DOE/FE, EPA, DOC, DOS, and several Academic Institutions, has performed several In-Country studies on the application of modem technologies for reducing the global Greenhouse Effect This program is also aligned with several financial institutions, the World Bank and the Asia Development Fund, for funding joint projects between US and PRC for implementing technologies for reducing the Greenhouse Effect.

Within the PRC, the central government has established a revitalization program called China's Agenda 21. This program calls out the specific industrial areas for modernization, identifies the environmental issues associated with the modernization, and proposes a cost share plan for implementing the required technologies to cleanup the environmental hazards afterwards. LLNL's Integrated Systems Analysis for Water Resources Management is a perfect tool for the PRC to evaluate and rethink some of the approaches associated with Agenda 21. In doing so, a more equitable partnership for investors may be found for modernizing the PRC industrial infrastructure because there would be less environmental hazards to be cleaned up.

\section{Southern Pacific Rim - Hong Kong, South Korea, and Singapore}

The paradigm for operating and developing business for LLNL with the governments in South Korea, Hong Kong, and Singapore are very much synergistic to that with the PRC. The endgame and the impact that LLNL will have in the global arena, however, are different with each of these countries. With the basic framework of doing business in mind, the following summarizes the objectives and important points in interacting with these governments and how to insert LLNL's Integrated Systems Analysis for Water Resources Management into these countries

LLNL has already established, through NASA, funded work with the country of South Korea for global and regional atmospheric modeling and surface hydrology modeling. The purpose is to provide a better understanding of how the climate will affect their watershed resources. The payback for these interactions with South Korea, besides contractual work, is in the political arena because the demonstration of the Integrated Systems Analysis techniques in helping South Korea fine tune their agricultural economy will have an impact on negotiation between US, South Korea, and Japan, with North Korea, a hard-line communist neighbor whose agricultural economy is collapsing because of mismanagement of their own limited watershed resources.

The interactions with Hong Kong is not focused on helping Hong Kong manage their watershed resources because Hong Kong receives all of their water allocations from the PRC. LLNL's interactions with the Hong Kong Environmental Protection Department and the Productivity Council are focused on equipping Hong Kong with the necessary tools to help the PRC after 1997, when Hong Kong reverts back to the PRC. Currently, Hong Kong has ample financial resources to acquire technologies and skills for helping the PRC after 1997, so that Hong Kong can gain political capital with the new government. An example of this is the funding of a Microturbulent Study by the Hong Kong Airport Port Authority to characterize the air patterns of the new airport currently under construction. This airport is jointly funded by the Hong Kong, Japan, and PRC governments (50/40/10 ratio, PRC is getting a real sweet deal) and will be equipped with the most modem technologies. The cost of the study is \$20M USD and \$15M of the total is contracted with the US National Center for Atmospheric Research (NCAR) in Boulder, Colorado

Singapore is also a small peninsula without a large watershed for its government to manage. However, it is the center of commerce for Thailand, Malaysia, and extends to India and the Philippines. Interactions 
with their government is focused on helping Singapore gain political capital with their neighbors in helping finance agricultural and industrial developments within its neighboring countries. The premise is that when the economy of these developing countries, based on agricultural and industrial developments, is stable, then the probability of regional conflicts will remain low.

\section{The Middle East - Israel, Jordan, and Palestine}

When Western media sources attempt to rationalize the violence from the conflict between Israel and her neighbors (the State of Palestine in the Gaza Strip and Jordan to the east), the interpretation has always focused on the spread of fanatical Islamic fundamentalism in the region. Yet this focus often distorts rather than clarifies the roots of violence, by giving insufficient consideration to underlying political, economic, and ecological conditions In many studies performed over the last five years, experts have concluded that the basis of the conflict, originally based on religious extremes, has now shifted to the issue of environmental scarcity and is directly tied to water scarcity and its impact on socioeconomic conditions.

Ironically, the Middle East peace process, if indeed can be achieved, offers an opportunity for the peoples in the region to redirect resources from security concerns to environmental activities and, in addition, to obtain international aid and foreign investment for the construction and improvement of environmental infrastructures that eventually could sustain industrial development, revitalize agricultural investments, and stabilize the population in the region. The new reality in the Middle East has guided the World Bank to submit to the international donor community an assessment of the development needs and prospects of two regions, whose stability and socioeconomic revitalization are deemed to crucial to the success of the Middle East peace process: the West Bank and the Gaza Strip.

LLNL's Integrated Systems Analysis for Water Resources Management can serve as the tool for both the US and Israel governments to strategically assess the water scarcity situation in the region, from which policies for restoration, reclamation, and remediation may be recommended The laboratory is aware of the sensitivities in dealing with both governments regarding the Middle East Peace Initiative, but the DOE and the national laboratories also recognize the impact and potential payoff if our technology can contribute directly to solving the water scarcity issues. The environment (water shortage, desertification, pollution) is playing a significant role in the Middle East peace process because it provides a confidence building measure and an end to facilitate regional understanding and cooperation among previously belligerent countries.

LLNL should begin the interactions regarding water scarcity issues in the Middle East with 1) the Department of State and 2) The Mediterranean Environmental Technical Assistance Program (METAP). METAP was initiated by the European Investment Bank and the World Bank in 1988, and was designed to help Mediterranean countries to cope with and reduce the effects of environmental degradation Besides funding from the two banks, METAP has a large program portfolio funded by the European Union, United Nations Development Program, and several bilateral international donors. Our interactions with the DOS and METAP will be focused on:

- the preservation and supplementing of water sources for the GAZA Strip addressing the issues of seawater encroachment, irrigation using saline water, contamination by fertilizers and pesticides, and infiltration of sewage, and

- the geographic and hydrogeologic effect of the West Bank in regard to the conveyance and penetration of rainfall into underground freshwater aquifer, and the impact of untreated sewage on the water resource. 


\section{Appendix I. Local and National Collaborators and Sponsors}

\section{Current and Previous Collaborators}

- University of California - Through the Campus-Laboratory-Collaboration (CLC) Program we began working with Scripps, UCLA, UCI, UCSB and UCD on water resource studies on the global, regional and watershed scales on time scales of hours to decades In addition, UCSB is involved with a small water quality study during the first year. This work is closely coupled with our present Exploratory Research LDRD project we have had for the past 18 months.

- National Weather Service (NWS) - For the past three years LLNL has been collaborating with the NWS with regard to precipitation forecasts over California They have used our products, in a research/test mode, to help with their flood forecasting particularly during the winter of 1995 . LLNL is now working with NWS to evaluate the atmospheric and surface hydrology model.

- US Navy Research Laboratory (NRL) - Two years ago, LLNL developed a collaboration with NRL that resulted in the Laboratory signing a Memorandum of Agreement that allowed the lab to bring their regional atmospheric models in-house, use them in our research and share research results. These models are now being applied to our water resource studies and they will eventually replace the UCD/LLNL model

- Korean Meteorological Research Institute (MRI) - The laboratory recently signed a Memorandum of Collaboration with MRI that allows us to share models and scientists in the scientific areas of precipitation and hydrology. We are now hosting a scientists from MRI and we have plans to participate with in a NASA/NWS study of the southeastern Asia monsoon This work will provide us and additional linkage into developing collaborative studies with China (discussed below)

- Orange County Water District (OCWD) - Our isotopic and groundwater modeling studies are being performed in collaboration with the OCWD. Historically, our earliest isotopic work was well received and allowed much of our more recent work to be funded directly by OCWD.

- City of Brentwood - Recent contractual work funded by the City of Brentwood used several isotopic analyses to forecast the long term viability of the current municipal well fields and suggest the most rational approach for future groundwater development.

\section{Potential Collaborations and New Sponsors}

- DOE Climate Program - At present DOE's climate program is largely focused on global climate studies, particularly the development, diagnosis and application of atmospheric and ocean models. There are hints that couple of changes may take place over the next several years. First, they have an increasing interest in coupled models that address atmosphere/oceans/biosphere and second, they will likely start addressing climate on regional scales since that is where concerns reside. Will the average snowline in the Sierra Nevada Mountains raise $500 \mathrm{~m}$ because of climate change or will the corn-belt receive less precipitation because of climate change? If so, what are the impacts to the surface and subsurface hydrology. Work support by this SI will place us in a leading position to address this type of question if DOE or any other agency moves in the direction of regional climate change.

- DOE (other programs) - DOE does not have a direct interest in water resources at the moment; however, they do have an interest and they fund studies related to processes that describe the growth and decay of certain cloud types These studies are a part of the Atmospheric Radiation Measurement (ARM) program in which we are involved as Science Team Members as well as participating as part of the scientific infrastructure support. This program can be a source of funding that compliments our Strategic Initiative investments.

- NASA - In our recent dialogues with Bob Harriss, Project Scientist for Mission Planet Earth, and several of his scientist, we have received very favorable comments regarding our approach to water resource studies, $i$ e., the "integrated systems" approach. They are in the first phase of planning for a 
"Center for Mid-Eastern Hydrology Studies" anchored to their present and particularly their near future satellite observations using advanced microwave technology. Using California as a testbed we can use analysis techniques based on our modeling and surface data to infer surface hydrology characteristics which can be used to study the Middle East water budget. We can seek support through the proposal or the contract process. We recently submitted a proposal titled "Global Climate Impact on Regional Hydro-Climate and its Effect on Southern Asian Agro-Ecosystems" (winners should be announced shortly) and we will be submitting one in the fall for a call associated with "Global Water Studies"

- EPA - EPA is in the process of trying to recover from allocating most all their research funds in the form of grants They are learning rapidly that a total grants program does not permit the Agency to build and achieve a well focused set of technical goals. In the past we have had funding from EPA through contracts and we believe we have a chance to win contracts in the future. EPA has interests in water resource issues that range the breadth of this Strategic Initiative. We presently have a proposal titled "Impacts of Global climate Variability on the Climate, Water Resources, Forests, and Crops of Southern United States". We believe EPA will be a viable funder in the next year or two, after their realignment and focus of their strategic policies in this area.

- Bureau of Reclamation (USBR) - The USBR is involved with a number of water resources issues, and, with respect to the State of California, have a strong and vested interest in the Central Valley water distribution system, as operator of the Central Valley Project (CVP) The USBR has funded a number of ground and surface water modeling studies related to ground and surface water balance issues over the entire valley and specific subbasins, as well as several studies focused on groundwater quality degradation associated with long term irrigation practices. We believe that several aspects of our proposed work could be of strong interest to the USBR.

- California - In the state interest and funding support is likely to come from the local water districts and counties than it is from the Department of Water Resources at this time. It appears that the local water districts and counties are more forward looking than the state as evidenced by our work with Orange county, City of Brentwood, and the work that in underway in the San Joaquin valley and proposed subsurface storage by the East Bay MUD We plan to investigate how we might enter these markets in the near future 


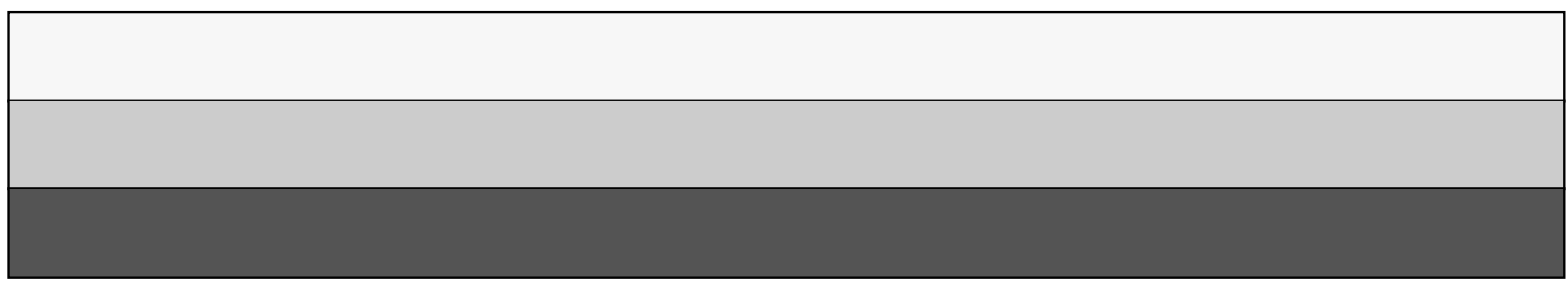

